Discussion

Papers
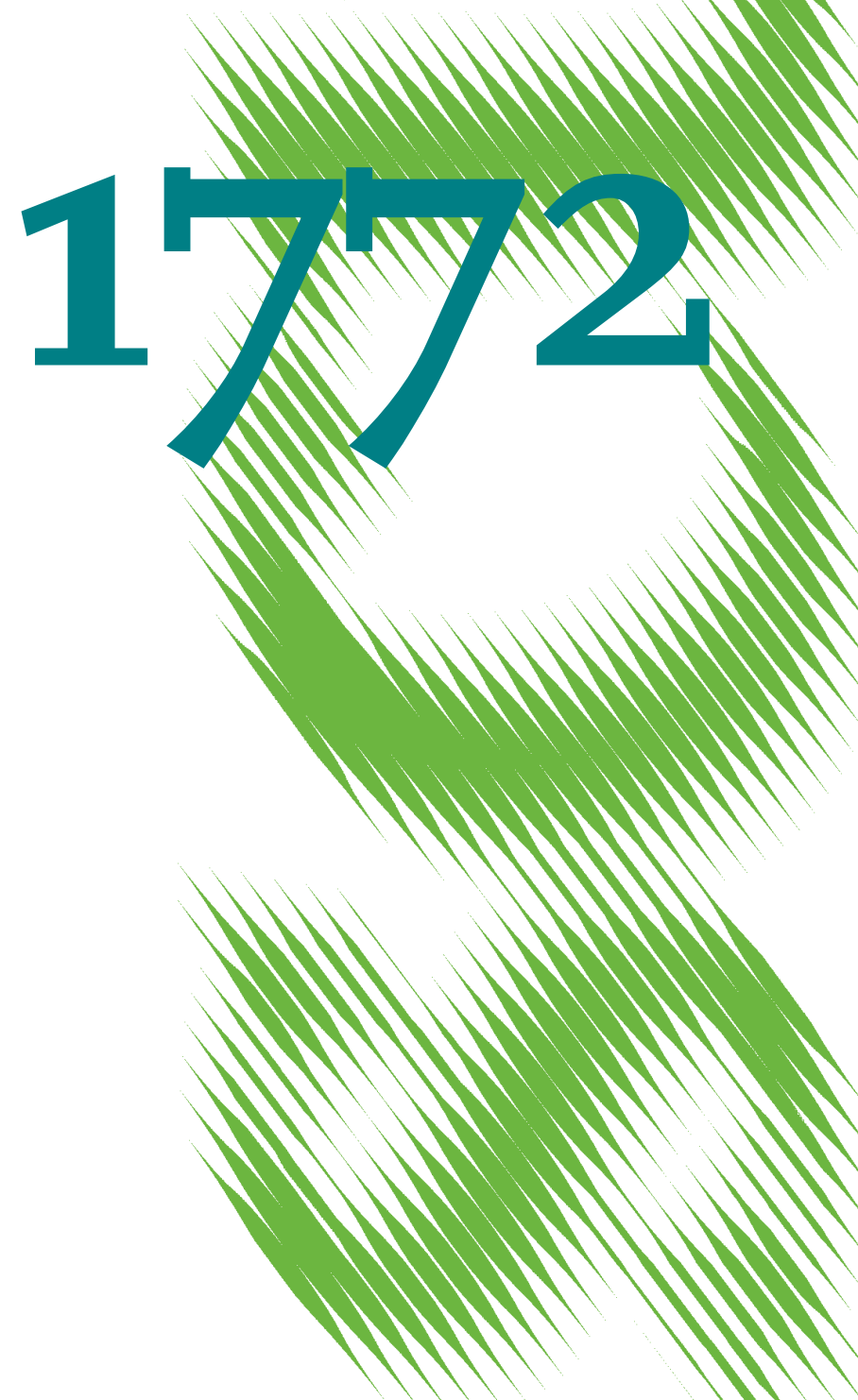

Do Laws Shape Attitudes? Evidence from Same-Sex Relationship Recognition Policies in Europe 
Opinions expressed in this paper are those of the author(s) and do not necessarily reflect views of the institute.

IMPRESSUM

(C) DIW Berlin, 2018

DIW Berlin

German Institute for Economic Research

Mohrenstr. 58

10117 Berlin

Tel. +49 (30) $89789-0$

Fax +49 (30) $89789-200$

http://www.diw.de

ISSN electronic edition 1619-4535

Papers can be downloaded free of charge from the DIW Berlin website:

http://www.diw.de/discussionpapers

Discussion Papers of DIW Berlin are indexed in RePEc and SSRN:

http://ideas.repec.org/s/diw/diwwpp.html

http://www.ssrn.com/link/DIW-Berlin-German-Inst-Econ-Res.html 


\title{
Do Laws Shape Attitudes? Evidence from Same-Sex Relationship Recognition Policies in Europe
}

\author{
Cevat G. Aksoy, Christopher S. Carpenter, Ralph De Haas, \\ and Kevin Tran
}

\begin{abstract}
Understanding whether laws shape or simply reflect citizens' attitudes is important but empirically difficult. We provide new evidence on this question by studying the relationship between legal same-sex relationship recognition policies (SSRRPs) and attitudes towards sexual minorities in Europe. Using data from the European Social Surveys covering 2002-2016 and exploiting variation in the timing of SSRRPs across countries, we show that legal relationship recognition is associated with a statistically significant increase in favourable attitudes towards sexual minorities. These effects are widespread across demographic groups, emerge only after the policies are adopted, and are not observed for views on other social issues. Our results suggest that laws can exert a powerful influence on societal attitudes.
\end{abstract}

JEL codes: $\quad$ F5; K36

Key words: Public opinion; Same-sex relationship recognition policies;

LGBT attitudes

\footnotetext{
Aksoy is a Principal Economist at the European Bank for Reconstruction and Development (EBRD) and a Research Associate at the London School of Economics and the IZA Institute of Labor Economics. Carpenter is a Professor of Economics at Vanderbilt University, Research Associate at the National Bureau of Economic Research, and a Research Fellow at the IZA Institute of Labor Economics. De Haas is Director of Research at the EBRD and a part-time Associate Professor of Finance at Tilburg University. Tran is a PhD student in economics at DIW Berlin. We are grateful for helpful comments from Nathan Anderson, Marcus Dillender, Sergei Guriev, Cindy Kam, Berkay Ozcan, Daniel Treisman, Nathaniel Young, and conference and seminar participants at Vanderbilt University, the 2018 AEA/ASSA meetings, the 2017 CREST/IZA/OECD Conference on Discrimination, and the 2017 APPAM Fall Research Conference. Results do not imply endorsement from the EBRD or any other organization. All interpretations, errors, and omissions are our own. Corresponding author: Kevin Tran (email: ktran@diw.de)
} 


\section{Introduction}

Scholars have long recognized the importance of understanding whether laws shape or simply reflect societal attitudes (Downs 1957, Besley and Case 2003, and others), but providing credible empirical evidence on this question has proven difficult. We present new evidence on this topic by using the gradual rollout of same-sex relationship recognition policies throughout Europe as plausibly exogenous policy variation to understand whether laws shape attitudes towards sexual minorities. Studying these policy changes is timely because advancements in civil rights for lesbian, gay, bisexual, and transgender (LGBT) individuals throughout Europe and the Americas have been some of the most striking social changes in recent decades. As recently as 2000, same-sex marriage was not legal in any European country; as of the time of this writing, same-sex couples can legally marry in 17 countries throughout Europe while same-sex registered domestic partnerships/civil unions are available in 11 others. Figure 1 shows that over this same period, the share of citizens who agree with the statement that "Gay men and lesbians should be free to live their own life as they wish” increased considerably - by about ten percentage points.

How might same-sex marriage and same-sex registered domestic partnership policies (henceforth: same-sex relationship recognition policies, or SSRRPs) affect attitudes towards sexual minorities? Flores and Barclay (2016) discuss four possibilities: backlash, legitimacy, polarization, and consensus. A backlash model predicts that attitudes towards LGBT people 
might become substantially more negative following legal recognition of same-sex relationships, especially in the case of judicial rulings. A legitimacy model predicts that legal rulings may increase acceptance and approval of LGBT populations as people infer the laws as increasing social legitimacy. A polarization model predicts that focusing on events such as major same-sex relationship policies may reduce ambivalence towards LGBT people and increase both social approval and disapproval of sexual minorities. Finally, a consensus model predicts that attitudes shape policy but that policy has no effects on attitudes. These alternative hypotheses make clear that ultimately the relationship between legal same-sex marriage and attitudes towards gay men and lesbians is an empirical question. We provide direct evidence on this question by using variation in the timing of the adoption of SSRRPs across a large set of European countries.

SSRRPs remain high on the policy agenda across the world, including in Australia, Europe, and Latin America. Understanding the impact of such policies on public attitudes is important for policymakers trying to gauge their social implications - particularly with respect to the risk of backlash and/or polarization. Our data allow us to examine whether relationship recognition policies have unintended negative effects on views towards sexual minorities for particular demographic groups such as men, rural populations, and religious individuals. Knowing whether there are adverse attitudinal effects for specific groups can help design policies to counterbalance any such spillover effects from SSRRPs. 
Our analysis uses data from the 2002-2016 European Social Surveys which asked over 325,000 individuals across Europe identically worded questions about a range of social and economic issues. Of particular interest is a specific question on whether the respondent agrees that "Gay men and lesbians should be free to live their own life as they wish". We use crosscountry variation in the timing of SSRRP adoption to estimate difference-indifferences models while controlling for individual demographic characteristics, country characteristics, other LGBT policies (such as nondiscrimination laws, adoption policies, and hate crimes legislation), country, year, and month fixed effects, and linear country-specific time trends.

To preview, we find that - consistent with a legitimacy model - laws do cause changes in attitudes. The introduction of a relationship recognition law for same-sex couples is associated with a statistically significant 3.6 percentage point increase in the likelihood that a respondent agreed that gay men and lesbians should be free to live their own life as they wish. This effect is about five percent of the baseline average. These results mean that the adoption of expanded relationship recognition policies for same-sex couples can explain 36 percent of the ten-percentage point increase over our sample period in the share of adults agreeing that gay men and lesbians should be free to live their own life as they wish (Figure 1).

Event study models confirm that the effects we identify emerge only after policy adoption, suggesting that the policies cause changes in attitudes (and not vice versa). We also show that the effects of same-sex relationship 
policies are unique to LGBT attitudes: there is no systematic relation between these policies and people's views on other social and economic issues (including attitudes towards other minority groups such as immigrants). Moreover, we document that the effects we identify are widespread across many demographic groups.

Our results also illustrate the importance of accounting for time invariant country-specific effects. Models that rely only on cross-sectional differences in the presence of SSRRPs across countries return associations between policies and attitudes that are three to ten times larger than our twoway fixed effects estimates. Thus, we find that policies both reflect and affect attitudes. Regarding the latter, our results suggest that attitudes towards sexual minorities are likely to improve further as the trend towards more countries adopting SSRRPs continues.

We proceed as follows. Section 2 reviews the literature on same-sex relationship recognition policies and attitudes towards LGBT people. Section 3 then describes the data and outlines our empirical approach. Section 4 presents the results after which Section 5 concludes.

\section{Related literature}

Only few papers have examined how same-sex relationship policies may be related to public opinion and attitudes. Like us, Takács and Szalma (2011) and Hooghe and Meeusen (2013) use European Social Survey (ESS) data but instead rely on cross-sectional designs. They find that individuals in countries 
with marriage equality had significantly more pro-LGBT attitudes than individuals in countries without relationship recognition for same-sex couples. Takács et al. (2016) use the 2008-2010 European Values Survey (EVS) to show that legislation permitting same-sex couples to adopt children is associated with respondents' views about whether homosexual couples should be allowed to adopt children. However, the cross-sectional nature of these research designs limits their ability to make credible causal claims.

Our study is more closely related to a recent working paper by Kenny and Patel (2017) who use the 1989-2014 World Values Survey data and the 2006-2016 Gallup World Poll data to estimate difference-in-differences models relating legalization of homosexuality to attitudes towards sexual minorities. They find evidence that when countries make homosexuality illegal, individuals are significantly more likely to state that they would not like to have a gay neighbor, less likely to state that homosexuality is justifiable, and more likely to state that their area is a bad place for gay men and lesbians to live.

Our contribution differs in several respects. First, and most importantly, we focus on relationship recognition policies instead of policies to make homosexuality illegal. Our results are therefore more germane for understanding shifts in attitudes in North and South America, where relationship recognition has recently been adopted or is on the current political agenda. We also employ different data (the European Social Survey, which we describe below) including a novel measure of attitudes towards sexual 
minorities. Importantly, we also explore heterogeneity in the effects of policies on attitudes towards sexual minorities to see whether policies widened or reduced pre-existing gaps in these views.

Our study is also related to two recent papers in political science that use individual-level panel data to examine the effects of same-sex marriage policies. Kreitzer et al. (2014) study a panel of individuals before and after Iowa’s state Supreme Court legalized same-sex marriage. They examine stated support for various relationship recognition statuses for same-sex couples and find that the law signaled new social norms which pressured some respondents to modify their expressed support. Flores and Barclay (2016) examine the effects of the 2013 rulings on same-sex marriage in the United States on attitudes towards LGBT people as measured by 'feeling thermometers' (in addition to questions about support for same-sex marriage). They find that people in states that introduced same-sex marriage saw the greatest reduction in anti-gay attitudes. They interpret this evidence as consistent with a legitimacy model and inconsistent with backlash or polarization models.

Unlike these two studies, we lack panel data to follow the same individuals over time. Our data and setting, however, do provide some unique advantages that allow us to complement prior work. Relative to the Kreitzer et al. (2014) study, for example, our paper examines effects of policies on mass attitudes towards LGBT people as opposed to support for specific policy proposals such as marriage equality. And unlike Kreitzer et al. (2014) and Flores and Barclay (2016), we are also able to test for heterogeneity in the 
relationship between same-sex relationship recognition policies and attitudes towards LGBT people.

Our work also contributes to recent research examining the determinants of homophobia and transphobia. Broockman and Kalla (2016), for example, performed a randomized experiment and find that conversations with residents in South Florida that asked participants to take the perspective of others significantly reduced prejudice, and that the effect persisted for three months. They also show that the intervention increased support for a nondiscrimination law. In contrast, this paper asks if public policies related to relationship recognition independently lead to meaningful changes in attitudes towards sexual minorities.

Finally, our paper is related to State and Wernerfelt (2017) who use data from Facebook profiles. The authors examine how state and federal court rulings on same-sex marriage impact individuals' social-media behavior including using the 'rainbow filter' to show support for same-sex marriage, 'liking' a page for LGBT rights organizations, or changing one’s relationship status. They find sharp changes in these LGBT-support measures coincident with the timing of legal same-sex marriage in the United States.

\section{Data description and empirical approach}

Our data on attitudes towards sexual minorities come from the 2002-2016 European Social Surveys (ESS). These surveys are fielded every year in over 
30 European countries and include questions on a range of topics. ${ }^{1}$ Our main sample includes over 325,000 respondents age 18 and older from 32 European countries. The key outcome variable in this paper comes from a question asked to all ESS respondents: "Do you believe that gay men and lesbians should be free to live their own life as they wish?’.2 We also examine responses to other questions about immigration and related social issues as placebo outcomes. We do not have information on the sexual orientation of ESS respondents, but most credible population-based surveys indicate that sexual minorities constitute a very small share of the overall population (generally between 1 and 3 percent of adults).

To estimate the effect of relationship recognition policies for same-sex couples on attitudes towards sexual minorities, we estimate standard difference-in-differences models that rely on plausibly exogenous variation in the timing of policy adoption across countries. These models take the form:

$$
\mathrm{Y}_{\text {ict }}=\beta_{0}+\beta_{1} \mathrm{X}_{\mathrm{ict}}+\beta_{2} \mathrm{SSRRP}_{\mathrm{ct}}+\beta_{3} \mathrm{Z}_{\mathrm{ct}}+\beta_{4} \mathrm{C}_{\mathrm{c}}+\beta_{5} \mathrm{~T}_{\mathrm{t}}+\beta_{6} \mathrm{C}_{\mathrm{c}} * \text { Trend }+\varepsilon_{\text {ict }}
$$

\footnotetext{
${ }^{1}$ The sample is an unbalanced panel because not all countries contribute data in every year.

${ }^{2}$ Other European surveys also ask questions about homosexuality and/or sexual minorities but do not provide sufficient coverage, in terms of countries and years, to support the two-way fixed effects empirical framework we use. Despite this, we have confirmed that our ESS 'free to live their own life as they wish' question is strongly correlated with questions from other European surveys when aggregated by country-year. For example, the 1990, 1999, and 2008 European Values Survey (EVS) asked: “On this list are various groups of people. Could you please sort out any that you would not like to have as neighbors?" 'Homosexuals' was one response option, so we can identify individuals who would prefer not to live next to a gay person. The 2010 and 2016 Life in Transition Survey (LiTS) includes a similar question. The EVS also included a question about the 'justifiability of homosexuality' on a scale of 1 to 10 , with 1 being 'always justifiable' and 10 being 'never justifiable'. The Gallup World Polls asks respondents whether their city or area is 'a good place to live for gay men and lesbians'. Appendix Table A1 presents a correlation matrix for our ESS measure and these other variables and shows that they are all strongly correlated in predictable ways.
} 
where $Y_{\text {ict }}$ is a variable indicating positive attitudes towards sexual minorities for individual $i$ in country $c$ at time $t$. $X_{\text {ict }}$ is a vector of standard individual characteristics: a Male dummy; Age and its square; dummy variables for Education categories (secondary and tertiary schooling, with less than secondary education as the excluded category); dummy variables for Marital/partnership status; a dummy variable for living in an Urban area; and dummy variables for religion (Orthodox Christian, Catholic, Protestant/Other Christian, Muslim, and Other religion, with atheist/agnostic/None as the excluded category). Same-Sex Relationship Recognition Policy (SSRRP) is an indicator variable equal to one in the countries and periods when same-sex marriage and/or same-sex registered partnerships/civil unions are legally available to same-sex couples. $^{3}$

We estimate linear probability models for ease of interpretation. ${ }^{4}$ The coefficient of interest is $\beta_{2}$, which in the presence of country and year dummies and country-specific trends (described below) is identified from sharp within-country changes in outcomes coincident with variation in the timing of policy adoption across countries. The key identifying assumption is

\footnotetext{
${ }^{3}$ We experimented with separate variables for same-sex marriage and same-sex registered partnerships/civil unions, but we do not have enough power to separately identify their effects. Also, in a few countries there was a lag between the legalization of same-sex marriage (enactment date) and the issuance of the first same-sex marriage licenses (effective date). For example, Finland approved same-sex marriage in December 2014, but marriage licenses for same-sex couples were not available until March 2017. Given that same-sex couples constitute a small fraction of the population and given that we think the treatment is mainly about the legitimization of same-sex couples by the government, we code the policy variables according to the enactment dates. In most cases, there was little time between the enactment and effective dates.

${ }^{4}$ We also estimate all models using probit and our results are virtually the same in terms of statistical and economic significance.
} 
that LGBT attitudes would have evolved identically in countries with and without relationship recognition policies had they not been adopted.

$Z_{c t}$ is a vector of other country-time varying policies and characteristics that may correlate with the policies we study. The data come from the International Lesbian, Gay, Bisexual, Trans and Intersex Association (ILGA) and various government webpages. These variables indicate whether the country has an explicit ban on same-sex marriage, whether the country's antidiscrimination protections include sexual orientation, whether the country permits adoption by same-sex couples, whether the constitution explicitly protects sexual minorities, and whether the country allows sexual orientationbased crimes to be classified as hate crimes. $Z_{c t}$ also includes the log of GDP per capita (in 2010 US Dollars).

$C_{c}$ and $T_{t}$ are a full set of country and year dummies, respectively. The former absorb time-invariant variation in the outcome variable caused by factors that vary across countries while the latter eliminate time-varying shocks that affect all countries simultaneously. We also include calendar month-of-interview dummies (not shown in equation 1). Lastly, we control for country-specific linear time trends by interacting each country fixed effect with a variable Trend that equals 1 in the first year of the sample, 2 in the second, and so forth. These trends remove variation in within-country attitudes towards sexual minorities due to factors that are country-specific over time. Sample weights make the data representative at the country level, and 
we cluster standard errors by country (Bertrand, Duflo and Mullainathan, 2004).

\section{Results}

\subsection{Descriptive statistics}

We first present descriptive statistics for the policy variables, LGBT attitudes, and individual demographic characteristics in Table 1. We provide means for the full sample in column 1 , for countries that had adopted SSRRPs by the end of our sample period in column 2, and for countries that did not adopt SSRRPs by the end of our sample period in column 3 .

The majority of respondents in our sample live in a country that had adopted legal same-sex marriage or registered domestic partnership/civil unions by 2016. Table 1 also shows that countries with legal relationship recognition for same-sex couples by 2016 were much more likely to have adopted other pro-LGBT policies such as employment protection for sexual minorities, the establishment of hate crimes laws covering sexual orientation, explicit constitutional protection for sexual minorities, and adoption rights for same-sex couples. Moreover, these differences are large, in the order of 30-50 percentage points between countries with and without legal relationship recognition policies for same-sex couples by the end of the sample period. This pattern suggests that unobserved fixed differences across countries may 
be important as well, an issue we address by using a quasi-experimental approach.

Table 1 also shows that individuals in countries with relationship recognition policies for same-sex couples were much more likely (40 percentage points or twice as likely) to agree with the statement that gay men and lesbians should be free to live their own life as they wish. These differences are much larger than the differences for questions related to immigrants (which are not very different across columns 2 and 3). We also see that differences in demographic characteristics across countries with and without legal relationship recognition for same-sex couples are small, with a few exceptions. One notable difference is the share of individuals who identify as religious: while less than 80 percent of individuals in countries that had same-sex marriage or registered domestic partnerships/civil unions by 2016 report a religion, the share reporting a religion in countries without legal relationship recognition for same-sex couples by 2016 is significantly higher at 91 percent. This pattern also underlines the importance of accounting for country fixed effects.

\subsection{Main results}

Table 2 presents our baseline estimates, based on equation (1), of the link between relationship recognition policies and attitudes towards sexual minorities. Each column reports a separate regression model, and we report the coefficient on the SSRRP indicator and the associated standard error. 
Column 1 reports results from a model where we only include the indicator for SSRRPs. We find that individuals in country/year combinations with same-sex relationship recognition have significantly more positive attitudes towards sexual minorities than individuals in country/year combinations without these policies. Specifically, we estimate that the presence of SSRRPs is associated with a statistically significant 40 percentage point higher likelihood of agreeing that gay men and lesbians should be free to live their own life as they wish. In column 2 we control for individual characteristics, country characteristics, and other LGBT-related public policies. When we add those covariates, the size of the association between SSRRPs and attitudes towards sexual minorities declines substantially. Yet, we still find that individuals in country/year combinations with SSRRPs are 9.3 percentage points more likely to agree that gay men and lesbians should be free to live their own life as they wish, as compared with otherwise similar individuals in places without SSRRPs.

The results in column 3 of Table 2 speak directly to the importance of accounting for time-invariant country-specific unobserved heterogeneity as well as smooth country-specific linear time trends. In this augmented model the SSRRP dummy is identified from sharp deviations off smooth trends in outcomes coincident with the timing of the relationship recognition policies across countries. These country-specific time trends are jointly significant predictors of the sexual minority attitude outcome (p-value $<0.01)$. Once we account for year and month fixed effects, country fixed effects, and linear 
country trends, we find that the association between same-sex relationship recognition policies and attitudes towards sexual minorities is reduced further in magnitude: it is about a third of the size of the model in column 2 and one tenth of the size of the model in column 1 . This is consistent with the idea that unobserved permanent cross-country differences and country-specific trends explain a substantial portion of the variation in support for sexual minorities, or put differently that laws reflect attitudes. We nevertheless continue to find that same-sex relationship recognition is associated with a statistically significant increase in the likelihood of agreeing with the pro-LGBT statement, an effect of about 3.6 percentage points. Relative to the base year sample mean, this is an effect of 5.3 percent. This pattern is consistent with the idea that laws affect attitudes. We consider the estimate in column 3 of Table 2 as our baseline estimate.

Figure 2 shows event-study estimates of the relationship between the adoption of legal SSRRPs and improved LGBT attitudes. The figure is based on our baseline specification (column 3 in Table 2) with linear country trends, a battery of individual covariates, and the full set of fixed effects. The sample consists of all countries that ever adopted a same-sex relationship recognition policy during our sample period. We follow Adukia et al. (2018) and exclude as our reference periods the year just prior to SSRRP adoption and the period for three or more years prior to SSRRP adoption. The event study estimates in Figure 2 provide evidence that relationship recognition policies for same-sex couples led to improved attitudes towards sexual minorities. Although few of 
the individual event time estimates are individually statistically significant, there is a noticeable immediate estimated increase in the likelihood of reporting that gay men and lesbians should be free to live their life as they wish. The broad pattern and magnitude matches the baseline difference-indifferences estimates in Table 2.

Returning to Table 2, we present in column 4 the results from a model where we exclude all of the LGBT policy controls except the relationship recognition variable to address possible concerns about collinearity among the various policies (though these models retain all the fixed effects and countryspecific time trends). We continue to find that same-sex relationship recognition policies are associated with statistically significant improvements in attitudes towards sexual minorities. Columns 5 and 6 of Table 2 show estimates based on a sample of only those 23 countries that ever adopted a relationship recognition policy (column 5$)^{5}$ or only the 13 countries that ever adopted a relationship recognition policy within our sample period (column 6). ${ }^{6}$ Our core findings are robust to these sample restrictions.

Next, in column 7 of Table 2, we show estimates for the sample of individuals in countries that were observed for at least 12 years during the 2002-2016 ESS period. Our result is robust to this sample restriction as well. Finally, in column 8 of Table 2 we report results from a model where we use

\footnotetext{
5 These countries are Austria, Belgium, Czech Republic, Denmark, England, Estonia, Finland, France, Germany, Hungary, Iceland, Ireland, Luxembourg, Netherlands, Northern Ireland, Norway, Portugal, Scotland, Slovenia, Spain, Sweden, Switzerland, and Wales.

6 These countries are Austria, Czech Republic, England, Estonia, Hungary, Ireland, Luxembourg, Northern Ireland, Scotland, Slovenia, Spain, Switzerland, and Wales.
} 
the Wild Cluster bootstrap procedure with 999 repetitions to account for the small number of clusters, and again our main finding is robust.

In Table 3, we strengthen inference further by showing that the relationship between SSRRPs and attitudes towards sexual minorities is unique to the LGBT domain. Specifically, we estimate similar models where we consider other outcome variables related to attitudes about non-LGBT issues such as immigration. If the timing of same-sex relationship recognition policies were correlated with other unobserved factors associated with more liberal or accepting societies in general, it would be incorrect to interpret the findings in Table 2 and Figure 2 as the effect of the relationship recognition policies on improving attitudes towards LGBT people. In this case, we might expect that the coefficient on same-sex marriage policies would be significantly related to more liberal attitudes on a range of issues and minority populations. $^{7}$

Each row of Table 3 presents a separate regression model using the fully saturated specification with country-specific linear trends as in column 3 of Table 2. We report the pre-reform outcome means in column 1. Column 2 shows the coefficient estimates for the key indicator variable of interest: whether the country has legal same-sex relationship recognition. We begin by reprinting the baseline estimates for the "gay men and lesbians should be free to live their own life as they wish" question in the top row of Table 3. Row 2 
then shows results for an outcome that equals one if the individual agreed that the country would be better if most people shared the same values. Row 3 shows results for an outcome that equals one if the individual agreed that immigrants cause crime. Row 4 shows results for an outcome that equals one if the individual agreed that immigrants put in more than they take out. Row 5 shows results for an outcome that equals one if the individual agreed that immigration enriches cultural life. Row 6 shows results for an outcome that equals one if the individual agreed that it is important to understand different people. Lastly, row 7 shows results for an outcome that equals one if the individual agreed that it is good to have a law against ethnic discrimination at the workplace. Together, these results confirm that the significant associations documented in Table 2 are unique to views about sexual minorities: we find no statistically significant associations between the availability of same-sex relationship recognition and any of the other attitudes in column 2 of Table $3 .^{8}$

In Table 4, we investigate heterogeneity in the effects of same-sex legal relationship recognition policies on attitudes towards sexual minorities. The format is the same as that of Table 3 except that we now examine associations for various demographic groups. In each case, the outcome in Table 4 is the same outcome as in Table 2 (i.e., agreeing that gay men and lesbians should be free to live their own life as they wish). Column 1 reports

\footnotetext{
${ }^{7}$ Of course, it is possible that there are 'real' spillover effects from relationship recognition policies to attitudes on other social issues, but we would expect any such spillovers to be small relative to the findings in Table 2.
} 
the mean of the LGBT attitude question for 2002-2004 (the beginning of the sample) for the sub-group identified in each row. We report the relevant policy coefficient estimates on the SSRRP indicator in column 2. As in Table 3 , each row reflects a separate regression that is fully saturated with controls for individual and country characteristics, country and time fixed effects, and linear country-specific time trends.

Column 1 of Table 4 reveals interesting descriptive heterogeneity in attitudes towards sexual minorities. For example, there is a notable gender difference: men report significantly more negative attitudes towards sexual minorities than women. There is also a substantial age effect: older individuals have significantly more negative attitudes towards sexual minorities than younger ones. Partnership, education, religion, and urban/rural differences are also observed clearly in the data. All of these differences are statistically significant at the 5 percent level.

The regression results in column 2 indicate that legal same-sex relationship recognition policies were associated with statistically and economically significant improvements in attitudes towards sexual minorities across a broad demographic spectrum. We do, however, find some interesting heterogeneity in the impact of relationship recognition policies. For example, column 1 showed that partnered individuals (i.e., those married or with a cohabiting partner) hold significantly more negative attitudes towards sexual

\footnotetext{
${ }^{8}$ We are admittedly limited in the range of 'placebo' questions we can examine because over the sample period the ESS did not consistently ask questions about, for example, views on
} 
minorities than non-partnered people. Importantly, in column 2 we also find that relationship recognition policies have larger effects at improving attitudes towards sexual minorities for partnered people than for non-partnered people. In contrast, however, we do not find similar evidence that relationship recognition policies work to “close the gaps” associated with age, education, or religious affiliation.

\section{Discussion and conclusion}

Do laws shape attitudes? Or do they simply reflect them? The results in this paper provide evidence that cross-country variation in policies towards sexual minorities reflects attitudes of the citizenry but also that such policies do have real effects in terms of shaping attitudes. Over our sample period, 13 countries adopted relationship recognition policies for same-sex couples. Our 2002-2016 data return evidence that such policies significantly improved attitudes towards sexual minorities. We also show that cross-sectional designs used in some of the prior literature tend to dramatically overstate the true causal relationship between policies and attitudes.

Event study estimates confirm that improvements in attitudes towards sexual minorities only occur after policy adoption, further suggesting that the policies change attitudes. The effects are unique to attitudes about sexual minorities and are broad-based across gender, age, education, and relationship status. We do, however, estimate notably stronger responses for partnered 
individuals who had systematically more negative attitudes towards sexual minorities at the beginning of the sample period.

What do our results suggest about the underlying structure of policies and attitudes? Recall that the political science literature on same-sex marriage and attitudes towards sexual minorities has considered four somewhat competing models of how legal same-sex marriage might be related to attitudes: backlash, legitimacy, polarization, and consensus (Flores and Barclay 2016). Our findings provide direct commentary on these candidate models. First, the findings from Europe - like those in Flores and Barclay (2016) for a single state in the United States - do not support the backlash model. In no case do we find that policies to legally recognize same-sex relationships are associated with a significant worsening of attitudes towards LGBT people. Second, the results also are broadly inconsistent with a model of polarization. That model would predict that some groups' attitudes would worsen while others would improve. We did not find much evidence for this at least as proxied by base period differences in attitudes towards sexual minorities. Third, the findings are also generally not supportive of the consensus model which predicts that there will be no effect on attitudes as the policies simply reflect changes in attitudes (and not vice versa). Instead, we find evidence that legal adoption of same-sex relationship recognition increases agreement with pro-LGBT views. This finding is most consistent with the legitimacy model whereby legal status confers legitimacy towards a particular group (here, sexual minorities), and attitudes adjust in response. 
Our results suggest that as marriage equality and other relationship recognition policies continue to expand throughout the world, we might expect to observe continued improvements in attitudes towards sexual minorities. This could translate into less discrimination (or more inclusion) in labor and housing markets, improved mental health for sexual minorities, and a range of other potential benefits associated with less anti-LGBT sentiment. 


\section{References}

Adukia, Anjali, Sam Asher, and Paul Novosad (2018). "Educational Investment Responses to Economic Opportunity: Evidence from Indian Road Construction”, working paper.

Bertrand, Marianne, Esther Duflo, and Sendhil Mullainathan (2004). "How Much Should We Trust Differences-in-Differences Estimates”, Quarterly Journal of Economics, 119(1): 249-275.

Besley, Tim and Anne Case (2003). "Political Institutions and Policy Choices: Evidence from the United States”, Journal of Economic Literature, 41: 7-73.

Broockman, David and Joshua Kalla (2016). "Durably Reducing Transphobia: A Field Experiment on Door-to-Door Canvassing”, Science, 6282.

Downs, Anthony (1957). "An Economic Theory of Political Action in a Democracy”, Journal of Political Economy, 65(2): 135-150.

Flores, Andrew R. and Scott Barclay (2016). "Backlash, Consensus, Legitimacy, or Polarization: The Effect of Same-Sex Marriage Policy on Mass Attitudes”, Political Research Quarterly, 69(1): 43-56.

Hooghe, Marc and Cecil Meeusen (2013). “Is Same-Sex Marriage Legislation Related to Attitudes Towards Homosexuality? Trends in Tolerance of Homosexuality in European Countries Between 2002 and 2010”, Sexuality Research and Social Policy, 10(4): 258-268.

Kenny, Charles and Dev Patel (2017). "Norms and Reform: Legalizing Homosexuality Improves Attitudes”, Center for Global Development Working Paper 465.

Kreitzer, Rebecca J., Allison J. Hamilton, and Caroline J. Tolbert (2014). "Does Policy Adoption Change Opinions on Minority Rights? The Effects of Legalizing Same-Sex Marriage”, Political Research Quarterly, 67(4): 795-808.

State, Bogdan and Nils Wernerfelt (2017). "Tipping in Social Norms: Evidence from the LGBT Movement”, working paper.

Takács, Judit and Ivett Szalma (2011). "Homophobia and same-sex partnership legislation in Europe”, Equity, Diversity and Inclusion: An International Journal, 30(5): 356-378. 
Takács, Judit, Ivett Szalma, and Tamás Bartus (2016). "Social Attitudes Towards Adoption by Same-Sex Couples in Europe", Archives of Sexual Behavior, 45(7): 1787-1798. 
Figure 1

Trends in Attitudes Towards Sexual Minorities

Outcome is share of people in the country who agree that "Gay men and lesbians should be free to live their own life as they wish" 2002-2016 European Social Survey Data, Adults age 18+

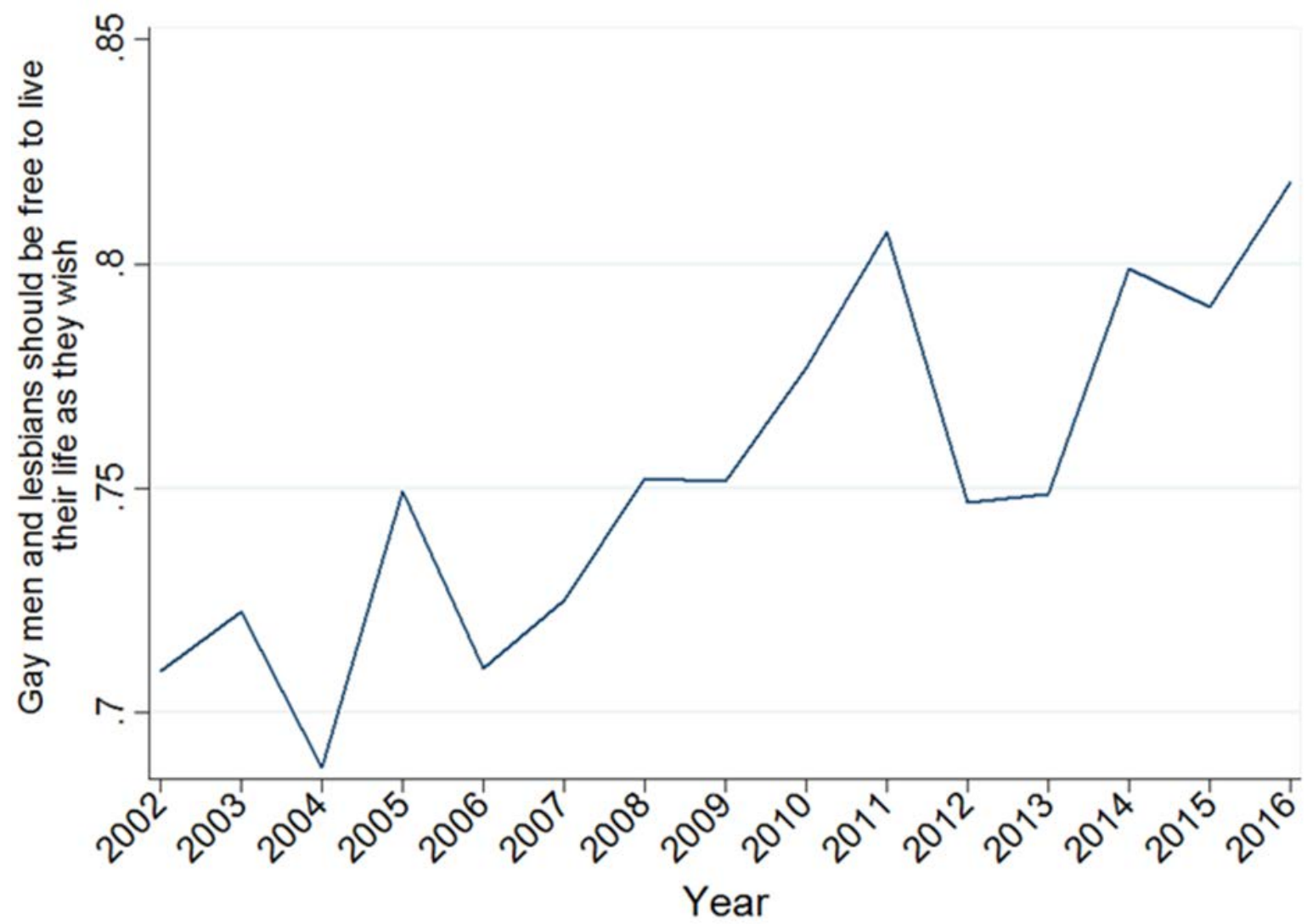

Note: This figure includes all countries that were observed during at least 10 years of the ESS. We further restrict the sample to observations used in the full-sample estimation. 
Figure 2

Event Study for Same-Sex Relationship Recognition 2002-2016 European Social Survey Data, Adults age 18+

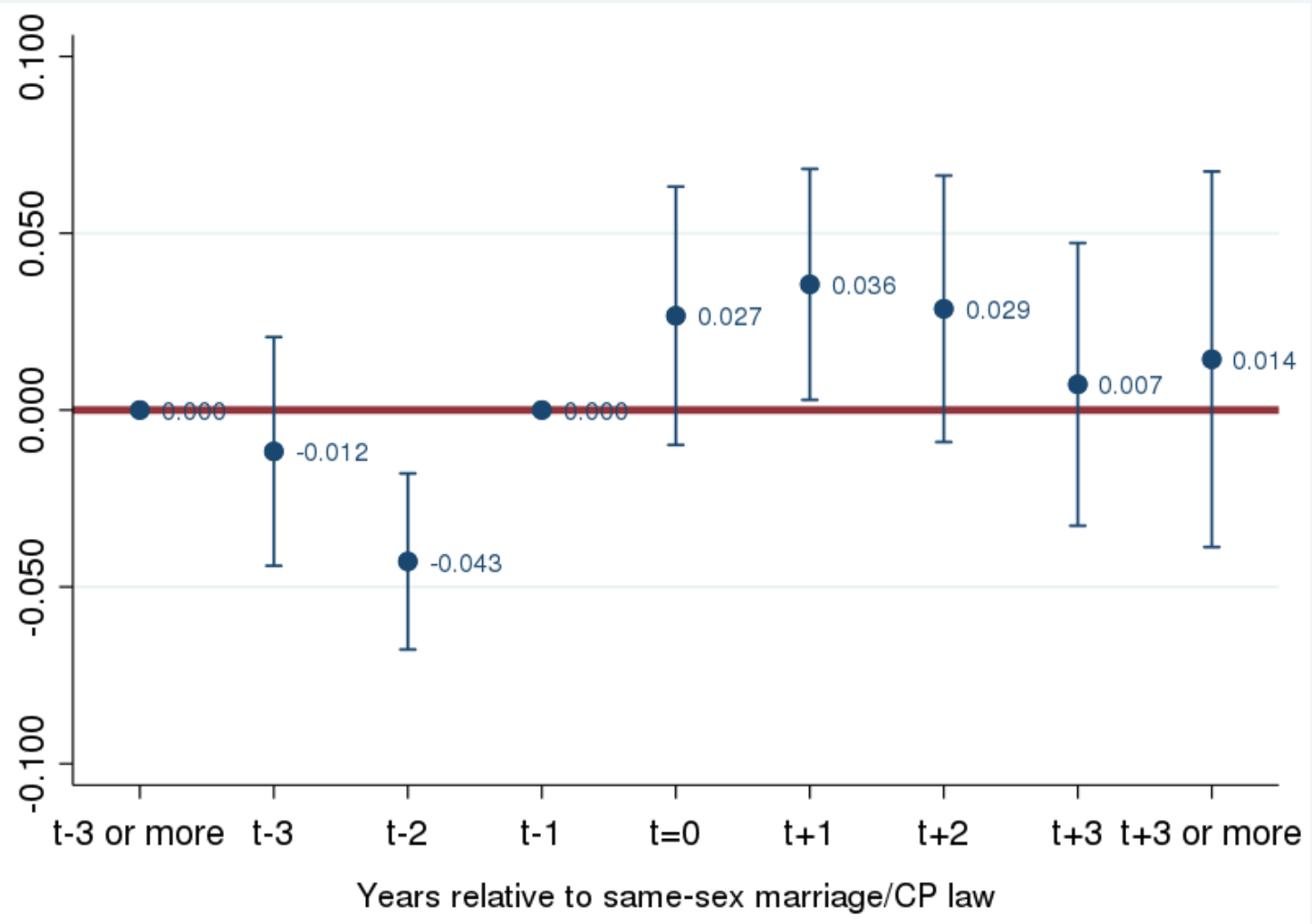

Note: This figure is based on the specification in column 3 of Table 2, which contains linear country-specific time trends. The sample consists of countries that ever adopted legal samesex marriage between 2001 and 2016. 
Table 1: Sample Characteristics

2002-2016 European Social Survey Data

\begin{tabular}{|c|c|c|c|}
\hline Variables & $\begin{array}{l}\text { (1) } \\
\text { Full sample }\end{array}$ & $\begin{array}{l}\text { (2) } \\
\text { Countries that had } \\
\text { relationship recognition for } \\
\text { same-sex couples by } 2016\end{array}$ & $\begin{array}{l}\text { (3) } \\
\text { Countries that did not have } \\
\text { relationship recognition for } \\
\text { same-sex couples by } 2016\end{array}$ \\
\hline \multicolumn{4}{|l|}{ LGBT public policies } \\
\hline Same-sex marriage/domestic partnerships legal & $0.56(0.49)$ & 1 & -- \\
\hline Constitutional ban on same-sex marriage & $0.14(0.34)$ & -- & $0.31(0.46) *$ \\
\hline LGBT employment protection & $0.69(0.46)$ & $0.92(0.27)$ & $0.40(0.49) *$ \\
\hline Hate crimes law for sexual orientation & $0.34(0.47)$ & $0.56(0.49)$ & $0.05(0.22) *$ \\
\hline Adoption legal for same-sex couples & $0.25(0.43)$ & $0.45(0.49)$ & $0.01(0.04) *$ \\
\hline Constitutional protection for sexual minorities & $0.20(0.40)$ & $0.36(0.48)$ & $0.01(0.10) *$ \\
\hline \multicolumn{4}{|l|}{ Attitudes towards minority groups } \\
\hline $\begin{array}{l}\text { Gay men and lesbians should be free to live } \\
\text { their own life as they wish }\end{array}$ & $0.62(0.48)$ & $0.80(0.39)$ & $0.40(0.49) *$ \\
\hline $\begin{array}{l}\text { Better for a country if almost everyone shares } \\
\text { customs and traditions }\end{array}$ & $0.46(0.49)-\mathrm{N}: 75,281$ & $0.41(0.49)-\mathrm{N}: 45,493$ & $0.55(0.49)-\mathrm{N}: 29,788^{*}$ \\
\hline Immigrants put in more than they take out & $0.15(0.36)-\mathrm{N}: 71,901$ & $0.15(0.36)-\mathrm{N}: 43,951$ & $0.15(0.35)-\mathrm{N}: 27,950$ \\
\hline Immigrants make crime problems worse & $0.06(0.24)-\mathrm{N}: 73,076$ & $0.06(0.24)-\mathrm{N}: 44,573$ & $0.06(0.23)-\mathrm{N}: 28,503$ \\
\hline Immigration enriches cultural life & $0.35(0.47)-\mathrm{N}: 310,764$ & $0.41(0.49)-\mathrm{N}: 186,630$ & $0.27(0.44)-\mathrm{N}: 124,134 *$ \\
\hline \multicolumn{4}{|l|}{ Individual demographics } \\
\hline Age & $48.70(17.95)$ & $49.64(17.84)$ & $47.51(18.04) *$ \\
\hline Male & $0.45(0.49)$ & $0.47(0.49)$ & $0.43(0.49)^{*}$ \\
\hline Less than degree level education & $0.69(0.46)$ & $0.72(0.44)$ & $0.65(0.47)$ \\
\hline Partnered & $0.53(0.49)$ & $0.53(0.49)$ & $0.54(0.49)$ \\
\hline Urban & $0.33(0.47)$ & $0.30(0.46)$ & $0.36(0.47) *$ \\
\hline Any religion & $0.84(0.36)$ & $0.79(0.40)$ & $0.91(0.28) *$ \\
\hline $\mathrm{N}$ & 326,069 & 191,840 & 134,229 \\
\hline
\end{tabular}


Table 2: Relationship Recognition Policies for Same-Sex Couples Significantly Improve Attitudes Towards Sexual Minorities

2002-2016 European Social Survey Data, Adults age 18+

Outcome is indicator for agreeing with "Gay men and lesbians should be free to live their own life as they wish"

\begin{tabular}{|c|c|c|c|c|c|c|c|c|}
\hline & $\begin{array}{c}(1) \\
\text { No controls }\end{array}$ & $\begin{array}{c}(2) \\
\text { (1) plus } \\
\text { controls for } \\
\text { individual } \\
\text { Xs, country- } \\
\text { specific } \\
\text { X's, and } \\
\text { other } \\
\text { country- } \\
\text { specific } \\
\text { LGBT } \\
\text { policies }\end{array}$ & $\begin{array}{c}(3) \\
(2) \text { plus } \\
\text { month and } \\
\text { year FE, } \\
\text { country FE, } \\
\text { and linear } \\
\text { country- } \\
\text { specific } \\
\text { time trends } \\
\text { [Baseline } \\
\text { model] }\end{array}$ & $\begin{array}{c}\text { (4) } \\
\text { (3) but } \\
\text { exclude all } \\
\text { other LGBT } \\
\text { policies }\end{array}$ & $\begin{array}{l}\text { (5) } \\
\text { (3) but only } \\
\text { countries } \\
\text { that ever } \\
\text { adopted } \\
\text { relationship } \\
\text { recognition } \\
\text { for same- } \\
\text { sex couples }\end{array}$ & $\begin{array}{l}\text { (6) } \\
\text { (3) but only } \\
\text { countries } \\
\text { that adopted } \\
\text { relationship } \\
\text { recognition } \\
\text { for same- } \\
\text { sex couples } \\
\text { within our } \\
\text { sample } \\
\text { window }\end{array}$ & $\begin{array}{l}\text { (7) } \\
\text { (3) but only } \\
\text { countries } \\
\text { observed in } \\
\text { at least } 12 \\
\text { of the } 14 \\
\text { years }\end{array}$ & $\begin{array}{l}\text { (8) } \\
\text { (3) but use } \\
\text { Wild cluster } \\
\text { bootstrap } \\
\text { with } 999 \\
\text { repetitions }\end{array}$ \\
\hline Mean, 2002-2004 & 691 & 691 & 691 & 691 & .729 & .683 & .716 & 691 \\
\hline $\begin{array}{l}\text { Relationship } \\
\text { recognition for } \\
\text { same-sex couples }\end{array}$ & $\begin{array}{c}.400^{* * *} \\
(.068)\end{array}$ & $\begin{array}{l}.093^{* *} \\
(.040)\end{array}$ & $\begin{array}{l}.036^{* *} \\
(.014)\end{array}$ & $\begin{array}{c}.030 * * * \\
(.011)\end{array}$ & $\begin{array}{l}.025^{* *} \\
(.011)\end{array}$ & $\begin{array}{l}.025^{*} \\
(.012)\end{array}$ & $\begin{array}{l}.032 * * \\
(.014)\end{array}$ & $\begin{array}{l}.036^{* *} \\
(.018)\end{array}$ \\
\hline $\begin{array}{l}\text { R-squared } \\
\mathrm{N}\end{array}$ & $\begin{array}{c}0.168 \\
326,069\end{array}$ & $\begin{array}{c}0.277 \\
326,069\end{array}$ & $\begin{array}{c}0.303 \\
326,069\end{array}$ & $\begin{array}{c}0.302 \\
326,069\end{array}$ & $\begin{array}{c}0.143 \\
255,307\end{array}$ & $\begin{array}{c}0.152 \\
112,623\end{array}$ & $\begin{array}{c}0.162 \\
165,853\end{array}$ & $\begin{array}{c}0.303 \\
326,069\end{array}$ \\
\hline \multicolumn{9}{|c|}{$\begin{array}{l}\text { Notes: * significant at } 10 \% ; * * \text { significant at } 5 \% ; * * * \text { significant at } 1 \% \text {. The individual characteristics are: a male dummy, age and its square, a } \\
\text { dummy variable for being unemployed, dummy variables for education categories (secondary and tertiary schooling, with less than secondary } \\
\text { education as the excluded category), a dummy variable for being partnered (married or living with a partner), a dummy variable for living in an } \\
\text { urban area, and dummy variables for religion (Orthodox/Catholic, Protestant, Jewish, Islamic, and other, with no religion as the excluded } \\
\text { category). Country characteristics include GDP per capita (in } 2010 \text { US Dollars). Other LGBT-related policies are: LGB employment } \\
\text { protection, hate crimes law for sexual orientation, adoption legal for same-sex couples, and constitutional protection for sexual minorities. } \\
\text { Results are weighted, and standard errors are clustered at the country level. }\end{array}$} \\
\hline
\end{tabular}


Table 3: No Effects on Placebo Outcomes

2002-2016 European Social Survey Data, Adults age 18+ Baseline Model from Column 3 of Table 2

\begin{tabular}{|c|c|c|}
\hline & $\begin{array}{c}(1) \\
\text { Mean of outcome } \\
(2002-2004)\end{array}$ & $\begin{array}{c}(2) \\
\text { Coefficient on } \\
\text { Relationship } \\
\text { Recognition for } \\
\text { same-sex couples } \\
\text { (standard error) }\end{array}$ \\
\hline $\begin{array}{l}\text { Gay men and lesbians should be free to live their } \\
\text { own life as they wish }\end{array}$ & .691 & $\begin{array}{l}.036^{* *} \\
(.014)\end{array}$ \\
\hline $\begin{array}{l}\text { Better for a country if almost everyone shares } \\
\text { customs and traditions }\end{array}$ & .513 & $\begin{array}{l}.235 \\
(.122)\end{array}$ \\
\hline Immigrants put in more than they take out & .137 & $\begin{array}{l}-.089 \\
(.256)\end{array}$ \\
\hline Immigrants make crime problems worse & .053 & $\begin{array}{l}.087 \\
(.070)\end{array}$ \\
\hline Immigration enriches cultural life & .408 & $\begin{array}{l}-.032 \\
(.021)\end{array}$ \\
\hline Important to understand different people & 955 & $\begin{array}{l}.005 \\
(.008)\end{array}$ \\
\hline $\begin{array}{l}\text { Good to have a law against ethnic discrimination at } \\
\text { the workplace }\end{array}$ & 626 & $\begin{array}{l}-.255 \\
(.247)\end{array}$ \\
\hline
\end{tabular}


Table 4: Effect Heterogeneity 2002-2016 European Social Survey Data, Adults age 18+ Baseline Model from Column 3 of Table 2

\begin{tabular}{lcc}
\hline & $(1)$ & $(2)$ \\
\hline & $\begin{array}{c}\text { Average of 'gay men and } \\
\text { lesbians should be free to } \\
\text { live their own life as they } \\
\text { wish' }\end{array}$ & $\begin{array}{c}\text { Coefficient on Relationship } \\
\text { recognition for same-sex } \\
\text { couples } \\
\text { (standard error) }\end{array}$ \\
\hline Full sample & .678 & $.036^{* *}(.013)$ \\
Males & .666 & $.039^{* *}(.016)$ \\
Females & .714 & $.035^{* *}(.014)$ \\
Above median age & .612 & $.030(.020)$ \\
Below median age & .762 & $.041^{* * *}(.011)$ \\
Less than degree level & .659 & $.032^{*}(.016)$ \\
Degree level education & .809 & $.053^{* * *}(.013)$ \\
Partnered & .670 & $.046^{* * *}(.016)$ \\
Not partnered & .717 & $.025^{*}(.014)$ \\
Rural & .675 & $.035^{* *}(.016)$ \\
Urban & .728 & $.034^{*}(.015)$ \\
Any religion & & \\
Atheist or no religion & .672 & $.035^{* *}(.013)$ \\
Notes: ${ }^{*}$ significant at $10 \% ; * *$ significant at $5 \% ; * * *$ significant at $1 \%$. See notes to Table 2.
\end{tabular}


Appendix Table A1: ESS Measure is Strongly Correlated with LGBT Attitudes Questions from Other Surveys

ESS 'Gay men
and lesbians
should be free
to live their own
life as they
wish' question

LiTS 'don't

want

homosexuals as

neighbors'

question

Gallup 'area is

a good place to

live for gay or

lesbian people,

question

ESS ‘free to live’ question

LiTS ‘neighbor’ question

$-0.919 * * *$

Gallup ‘area’ question

$0.958 * * *$

$0.870 * * *$

EVS 'justifiability'

question

EVS 'never justified'

$-0.876 * * *$

$0.878^{* * *}$

$-0.925^{* * *}$

$-0.974 * * *$

EVS

EVS

EVS

‘justifiability of

'homosexualit

is never

'homosexuality

ustified

is always

EVS ‘always justified' $\quad 0.884^{* * *} \quad-0.781^{* * *} \quad 0.834^{* * *} \quad 0.947^{* * *} \quad \begin{array}{lll}-0.853^{* * *} & 1\end{array}$

Notes: *** significant at $1 \%$. Author calculations, various datasets. 